$12-2019$

\title{
El laberinto de regreso al pasado hacia el futuro: la influencia de Borges en Beltenebros de Muñoz Molina
}

Tanya Romero-González

Murray State University, tromerogonzalez@murraystate.edu

Follow this and additional works at: https://digitalcommons.murraystate.edu/faculty

Part of the Spanish and Portuguese Language and Literature Commons

\section{Recommended Citation}

Romero-González, Tanya. "El laberinto de regreso al pasado hacia el futuro: la influencia de Borges en Beltenebros de Muñoz Molina." Hispanófila 187.1 (2019): 63-78. https://doi.org/10.1353/hsf.2019.0054

This Journal Article is brought to you for free and open access by the Faculty Works at Murray State's Digital Commons. It has been accepted for inclusion in Faculty \& Staff Research and Creative Activity by an authorized administrator of Murray State's Digital Commons. For more information, please contact msu.digitalcommons@murraystate.edu. 


\title{
EL LABERINTO DE REGRESO AL PASADO HACIA EL FUTURO: \\ LA INFLUENCIA DE BORGES EN BELTENEBROS DE MUÑOZ MOLINA
}

\author{
Tanya Romero-González
}

Murray State University

\begin{abstract}
The present article explores the connections between Antonio Muñoz Molina's Beltenebros (1989) and Jorge Luis Borges' work. Specifically, I examine how the reappearance of the past is depicted in Muñoz Molina's novel as compared to Borges' short stories "La muerte y la brújula" and "El sur" and how these connections are embedded in wider critical discourse about memory, history and their postmodernist reinterpretations. While other critics have pointed to the connection between these two authors, my comparative analysis reveals the depth of the socalled Borges effect. Firstly, the doubling of characters and the interconnections among them suggest the necessity of having duplicate or triplicate identities to deal with the past. Secondly, labyrinthine and oneiric paths confound characters — and readers - leading them into uncanny places where heroes, cowards and traitors commingle. Lastly, by exploring the recurrence of simulacrum, anachronism and symmetry in these works, we see that both authors suggest that fiction is an intrinsic and complementary part of reality. However, while most of the protagonists of these works appear to be trapped in the past, in Beltenebros the ending points to the realization that in order to access the future it is necessary to find a way through the past.
\end{abstract}

El influjo literario entre autores, capaz de trascender fronteras geográficas, lingüísticas y temporales, obedece, en parte, a una técnica adaptativa de supervivencia. El conjunto de escritores contemporáneos sobrevive - es decir, publica — haciendo uso de las fórmulas literarias de sus antecesores, adecuándolas al ambiente que le rodea. Esta huella permanece en un código 
genético literario heredado que podrá hacerse presente de forma más o menos pronunciada. Una de las influencias determinantes es la de Jorge Luis Borges, quien no sólo marca a escritores posteriores, sino que también consigue redefinir a autores precedentes ${ }^{1}$. Bajo este prisma, el efecto Borges, por una parte, es indeleble, al igual que la cicatriz que surca la cara del segundo narrador de "La forma de la espada", y que acabará delatando su traición. Por otra, está destinado a manifestarse incluso después de una postergación, tal y como ocurre en "El milagro secreto" con la gota de lluvia en la mejilla de Jaromir Hladík que, junto con las balas que van dirigidas a él, reanuda su camino después de que el condenado complete su obra de teatro delante de un pelotón de fusilamiento temporalmente paralizado.

Entre los autores contemporáneos que revelan la impronta borgeana se encuentra el escritor español Antonio Muñoz Molina. En el presente artículo exploraré la génesis de esta conexión, las similitudes en el credo artístico, así como la técnica narrativa de ambos autores. Para ello, llevaré a cabo un estudio comparativo y contrastivo entre la novela Beltenebros (1989) de Muñoz Molina y dos de los relatos más significativos en la extensa obra de Borges: "E1 Sur” y "La muerte y la brújula", con especial énfasis en el persistente regreso del pasado².

Antes de abordar el análisis interpretativo de los textos conviene delinear el contexto crítico en el que se incardinan ambos autores. Muñoz Molina ha sido incluido principalmente en la corriente postmodernista, mientras que Borges ha sido denominado tanto modernista—en el

\footnotetext{
${ }^{1}$ Esta repercusión literaria bidireccional está especialmente presente en el proceso de traducción que, para Borges, implica un método de reescritura. Sergio Waisman explora la figuración de Las mil y una noches en Argentina, destacando el enfoque borgeano que pondera la importancia de que los escritores "incorporate previous traditions, the legacy of the past, through irreverent rereadings and rewritings of previous texts" (356). Así, la creatividad no tiene límites y, tal y como Borges subraya en una de sus inquisiciones acerca de Kafka y sus antecesores, "cada escritor crea a sus precursores" (166). Según esta perspectiva, no sólo es inevitable, sino necesario, integrar y transformar la tradición literaria.

${ }^{2}$ Joaquín Marco establece un enlace directo entre la novela de Muñoz Molina y el escritor argentino al declarar que "Jorge Luis Borges nunca llegó a escribir una novela, pero, si hubiera escrito alguna, se parecería a Beltenebros" (cit. en Mas 168). Es difícil hacer tal aseveración, aunque es cierto que, debido a las características de la prosa de Muñoz Molina, Borges habría encontrado elementos en la novela que probablemente habrían sido de su agrado.
} 
sentido anglosajón del término—como postmodernista. ${ }^{3}$ Esto se debe en parte a lo que Jaime Alazraki denomina el "problema inherente" entre estos períodos que, como dice el crítico, se han visto, por un lado, como una continuidad el uno del otro y, por otro, como una bifurcación (“Borges: Entre la modernidad y la postmodernidad” 176). Tal y como asevera Douwe F. Fokkema, Borges transciende el modernismo para convertirse en un abanderado del movimiento postmodernista: "It can be argued that Postmodernism is the first literary code that originated in America and influenced European literature, with the possibility that the writer who contributed more than anyone else to the invention and acceptance of the new code is Jorge Luis Borges. .." (38). De forma similar, Muñoz Molina realiza un movimiento pendular entre el modernismo y el postmodernismo. Así, según Jo Labanyi, en Beatus Ille (1986), obra anterior a Beltenebros, el escritor español delinea "a seemingly conventional recuperation of the past through memory" mientras que posteriormente Muñoz Molina escribe "a series of overtly postmodernist pastiches of the thriller genre" ("Postmodernism" 402). Aunque Labanyi no menciona específicamente Beltenebros, en esta novela Muñoz Molina cuestiona el concepto de autor a través de su uso de una narración en que la representación de la historia por medio de la (des)memoria se pone en duda. Si bien mi intención no consiste en entrar en un debate terminológico en cuanto al encasillamiento de estos autores dentro de estas corrientes literarias, usaré el concepto de postmodernismo en mi análisis para poner de relieve la conexión entre Muñoz Molina y Borges así como la relevancia del contexto crítico en el que aparecen sus obras.

Además de la repercusión de las corrientes teóricas que rodearon e influenciaron a estos

\footnotetext{
${ }^{3}$ La importancia de Borges para el postmodernismo es delineada por Bran Nicol que a su vez señala la naturaleza compleja de situar a Borges, junto con otros autores, en una corriente específica: "Beckett, Borges, and Burroughs occupy a somewhat liminal position with regard to the two most significant movements in twentieth-century fiction: not modernist yet not postmodernist, even though their work is the foundation upon which postmodernist writing rests" (52). Por tanto, mientras el influjo de Borges en el postmodernismo es innegable, su producción literaria e impronta en la crítica literaria es inabarcable.
} 
autores en distinta medida, Muñoz Molina ha expresado la importancia de la literatura latinoamericana, en general, y Borges, en particular, en la formulación de su definición del arte literario así como en su desarrollo como escritor. Muñoz Molina alude a la lectura de las obras latinoamericanas que comenzaron a emerger durante su juventud bajo la dictadura franquista no sólo como una tabla de salvación personal, sino también como un resurgimiento de las letras escritas en español:

En torno a Cien años de soledad siguieron llegándonos libros que nos alimentaban la imaginación y el conocimiento de América, y que nos hacían tomar conciencia de las dimensiones inusitadas de nuestro idioma. Fue una orgía perpetua que cambió en unos pocos años la literatura en español, una edad de oro que nos deslumbra menos porque nos hemos acostumbrado a ella. (s.p.

"Discurso")

En la misma línea, Pablo Sánchez López se incursiona en delinear el reencuentro entre el público lector español y la literatura latinoamericana, especialmente a través de la figura de Alejo Carpentier que, además de publicar su primera novela en España, revive la apertura del mundo editorial español para las obras de otros escritores latinoamericanos, con la llegada de El siglo de las luces, publicado tardíamente en España en 1965 (102, 109). Según Sánchez López, esta evolución editorial "se reajusta y empieza a adaptar a la valoración general de la crítica europea, para la que Asturias, Carpentier y Borges gozan ya de un status de prestigio" (109). En este panorama literario, Muñoz Molina reconoce el impacto que supuso leer a Borges para su futuro profesional: "Yo creo, sinceramente, que mi trabajo como escritor y el de muchos escritores de mi generación no habría sido de ninguna manera el mismo sin el ejemplo de Borges . . . La lectura de 'El Aleph' me descubrió lo que yo verdaderamente quería hacer" (“Una celebración”). 
El efecto Borges es, por tanto, reconocido y enarbolado con orgullo por el escritor español.

La conexión entre Borges y Muñoz Molina es especialmente prominente en Beltenebros, una de sus primeras novelas ${ }^{4}$. El título del libro constituye una referencia explícita a Don Quijote, pues se trata del protagonista de Amadís de Gaula, uno de los intertextos esenciales de Don Quijote. Muñoz Molina enfatiza la importancia del título al aludir a la inmensa capacidad ficticia que abarca y que le inspiró para escribir la novela: "Un nombre leído en El Quijote y recordado siempre porque contiene entera una historia: Beltenebros" (cit. en Mas 165). Así, el influjo literario, como ocurre con otros escritores, no se limita al efecto Borges y puede ser rastreado hasta la saciedad. Muchos rasgos cervantinos son, a su vez, compartidos por Borges y otros escritores por lo que en algunos casos es difícil delinear las conexiones intertextuales. No obstante, en el caso de Beltenebros la influencia borgeana es tal que merece ser estudiada aparte. En la novela de Muñoz Molina, Darman, el protagonista, atribuye erróneamente el nombre de Beltenebros a Walter, un camarada de la organización de la que forman parte y que, aunque no se menciona explícitamente en ningún momento, corresponde al PCE—Partido Comunista de España. Sin embargo, descubre posteriormente que el verdadero príncipe de las tinieblas es el comisario Ugarte quien, a su vez, es también Valdivia, otro miembro del PCE al que Darman creía muerto heroicamente hace años. Este malabarismo onomástico no se detiene aquí, tal y como podremos comprobar en la siguiente elucidación de la trama de la novela. La narración está focalizada a través de la perspectiva de Darman, centrándose en dos casos de espionaje que acontecen en puntos cronológicos distantes, si bien, en ambos casos, Darman es uno de los personajes principales. Durante sus años de juventud el protagonista era uno de los

\footnotetext{
${ }^{4}$ En un relato anterior de Muñoz Molina, "Carlota Fainberg"-posteriormente ampliado para constituir una novela publicada en 1999 - Borges ya aparece mencionado reiteradamente, ya que es parte central del relato: el protagonista es un profesor universitario que se dirige a una conferencia a presentar una ponencia sobre "Blind Pew" y se insertan varias referencias y análisis que versan sobre Borges y su obra.
} 
miembros clave del latente PCE, convirtiéndose más tarde en una vieja gloria exiliada del movimiento clandestino de resistencia comunista.

La confianza que la organización deposita en Darman se evidencia en las misiones que se le asignan. Se le encarga, en dos ocasiones distintas, asesinar a camaradas que supuestamente han traicionado su fidelidad al PCE. El “caso Walter" se desarrolla en los años inmediatamente posteriores a la guerra civil, durante la década de los cuarenta, mientras que el "caso Andrade" tiene lugar en los años sesenta. La narración, mediante constantes movimientos analépticos, transforma la misión de matar a un hombre en una persecución del pasado del protagonista. Este pasado se materializa en el aparente resurgir de la pareja de Walter, una mujer llamada Rebeca Osorio, que se encuentra en el centro de la intriga y que parece mágicamente inmune al transcurso del tiempo. Esta mujer, que interpreta mientras realiza un striptease hasta quedarse desnuda, una versión de la canción de Rita Hayworth "Put the Blame on Mame” en un tugurio en la década de los sesenta, resulta que no es la misma Rebeca Osorio que produce obsesivamente novelas sentimentales que incardinan mensajes crípticos para el PCE en los cuarenta. Las dos son, de hecho, madre e hija, aunque la joven Rebeca Osorio ha estado distanciada y aislada de su progenitora desde su niñez. En este sentido, somos testigos de una reencarnación postmoderna del pasado ya que, como argumenta Linda Hutcheon, "[ $\mathrm{t}]$ he past as referent is not bracketed or effaced . . . : it is incorporated and modified, given new life and meaning" (182). Rebeca Osorio da vida a una versión del pasado capaz de transcender, como veremos, el peso de su propia historia.

El desenlace de la novela tiene lugar en el Universal Cinema en ruinas de antaño, un edificio que está conectado mediante un túnel al club boîte Tabú. Por medio de esta estructura meándrica, tiempo, espacio y personajes acabarán concurriendo al final de la novela. Rebeca 
Osorio-madre, sumida en un desequilibrio mental, ha sido encerrada en una de las habitaciones del cine, escribiendo una novela invisible en una máquina de escribir carente de papel. Su hija es atada desnuda y—aparentemente—indefensa por la personificación de la trinidad perversa: el agente doble Valdivia, el torturador franquista Ugarte y el mítico Beltenebros, que resultan ser la misma persona. En un momento clave de anagnórisis, Darman resuelve el rompecabezas tras vincular la intolerancia a la luz que rodea a todos estos personajes. En la profunda negrura del patio de butacas, el nictálope Beltenebros y Darman inician un duelo que concluye gracias a la intervención de Rebeca Osorio-hija, que esgrime una linterna, cegando a Beltenebros y causando su mortal caída ${ }^{5}$.

La sinopsis de la trama de la novela de Muñoz Molina apunta a unos paralelos interesantes con los relatos y personajes borgeanos. En primer lugar, el nombre del protagonista de Beltenebros, "Darman", tiene una clara similitud con Dahlmann, el personaje principal de "El Sur" ${ }^{6}$. Además, estos personajes manifiestan un desarrollo similar. Juan Dahlmann, en su retorno a casa tras su estancia en un sanatorio, parece reencontrar el vecindario bonaerense de Constitución, experimentando un proceso de reconocimiento a través de su recuerdo de la ciudad: "Dahlman la reconocía con felicidad y con un principio de vértigo; unos segundos antes

\footnotetext{
${ }^{5}$ A pesar de que el texto establece esta conclusión sin ningún tipo de ambigüedades, existe una persistencia extendida en la crítica, que adjudica el asesinato de Beltenebros a Darman en lugar de a Rebeca Osorio. Winter establece que, en el Universal Cinema, Darman "se liberaría de su pasado al liberar a la joven Rebeca y matar a Ugarte" (202). El uso del tiempo condicional es acertado dado que se puede cuestionar si realmente Darman se evade de su pasado. No obstante, la presuposición que instituye a Darman como héroe, Ugarte como traidor y Rebeca como víctima, es errónea, puesto que, los hechos narrados en el desenlace, por un lado, y la porosidad de estos conceptos, por otro, no admiten esa etiquetación superficial y sesgada. Esta descaminada línea interpretativa es también seguida por Pasqual Mas, quien asevera que "Darman no es el héroe por matar a Walter y provocar la muerte de Andrade: es un héroe por acabar con Beltenebros" (91). La única notable excepción es el artículo de Epicteto Díaz Navarro que apunta a que la novela misma niega las lecturas anteriores ya que la joven Rebeca Osorio es la que enarbola la mortífera linterna que acaba con Valdivia.

${ }^{6}$ Otra semblanza literaria entre estos escritores es que ambos crean unos espacios concretos y teñidos de una pátina imaginaria en sus obras. Para Borges el Sur es una dimensión real y a la vez ficticia. Muñoz Molina, sitúa gran parte de su obra - aunque no es el caso en Beltenebros — en una ciudad inventada, Mágina, con base real en su ciudad natal. Muñoz Molina sigue la línea de otros escritores como William Faulkner y Gabriel García Márquez que radican sus historias en los lugares ficticios como Yoknapatawpha y Macondo, respectivamente.
} 
de que las registraran sus ojos, recordaba las esquinas, las carteleras, las modestas diferencias de Buenos Aires. En la luz amarilla del nuevo día, todas las cosas regresaban a él” (214). De forma similar, en Beltenebros Darman vuelve a Madrid desde su exilio inglés con una misión asesina:

Dejó de llover y vi la última luz del sol sobre los árboles y los edificios de la Castellana, una luz muy fría que destellaba contra el pálido azul en lo más alto del edificio de Correos ... Cada vez que volvía a Madrid era como si perdiese la piel de indiferencia y olvido que el tiempo había agregado a la memoria. (158) Ambos protagonistas describen esta experiencia como si se tratara de un renacer de su identidad pasada a través de este reencuentro con un entorno familiar. Así, el fulgor que trae consigo el nuevo día implica para Dahlmann la esperanza de dejar atrás su enfermedad pasada, mientras que la puesta de sol que acompaña su retorno a la capital supone para Darman una pérdida de la capa protectora con la que pretende resguardarse del pasado. Además, tanto Dahlmann como Darman perciben sus respectivos periplos como una suerte de viaje en el tiempo. En "El Sur" se apunta a esta posibilidad: "Dahlmann pudo sospechar que viajaba al pasado y no sólo al Sur" (216). En Beltenebros el reencuentro final de Darman con una enajenada y ajada Rebeca Osorio contrasta con las escenas fantasiosas de la reunión que ha imaginado durante dos décadas, según las cuales coincidirían "no en esta ciudad a la que ahora había vuelto, sino en el Madrid en blanco y negro del pasado" (279). Análogamente, en "La muerte y la brújula" el detective Erik Lönrot sigue una serie de pistas con el objetivo de resolver un crimen que le devuelve al pasado, donde será asesinado por Red Scharlach en venganza por la encarcelación de su hermano, tres años atrás. Por tanto, la persistente presencia del pasado es recurrente en estas obras. En este sentido Labanyi, en su apropiación del término derridiano de hauntology, emplea esta noción para referirse a este tipo de reaparición de un pasado donde "the status of history ... is that of a 
ghost haunting the present: not there but there" ("History and Hauntology" 68). Este término permite que la historia y la memoria converjan en un giro postmodernista ya que la memoria de los personajes se ve afectada por la historia: tanto en la novela de Muñoz Molina como en los relatos de Borges existe una persecución y asedio no sólo de la historia personal de los protagonistas, sino también de la Historia, manifestándose inevitablemente en el presente, tal y como podremos comprobar. Asimismo, ambos autores concluyen sus obras con la muerte-ya sea literal, figurada o soñada — de uno de sus protagonistas. No obstante, en la obra de Muñoz Molina, aunque muere Valdivia-Ugarte-Beltenebros, Darman sobrevive y la joven Rebeca Osorio consigue erradicar la presencia nociva de su némesis, apuntando a que es posible transcender el pasado/la historia.

Una de las formas en las que el pasado converge con el presente es por medio del anacronismo, las duplicaciones y las simetrías. Esta ruptura con lo singular e individual se encuentra en la línea del postmodernismo puesto que éste "deconstructs the concept of unityand by extension that of identity, in its sense of 'sameness' - exposing it as a political manoeuvre designed to suppress recognition of difference within" (Labanyi, "Postmodernism” 397). Así, tanto Borges como Muñoz Molina revelan, a través del énfasis en los continuos desdoblamientos, anacronismos y simetrías, el carácter maleable de la historia y la memoria.

En "El Sur" el narrador, comentando sus viajes hacia y desde el sanatorio declara que "[a] la realidad le gustan las simetrías y los leves anacronismos" (213), mientras que en "La muerte y la brújula" la pesquisa llevada a cabo por Lönrot en relación con los asesinatos se centra en los paralelos temporales y espaciales. Cuando el investigador llega a Triste-Le-Roy, la casa donde los crímenes son resueltos simultánea e irónicamente, intenta racionalizar el sentimiento uncanny que permea el ambiente, adscribiéndolo a los espejos y la simetría. Esta sensación de encontrarse 
ante algo uncanny, definido por Sigmund Freud como "that class of the terrifying which leads back to something long known to us, once very familiar", apuntando al efecto turbador de lo familiar desfamiliarizado (369-70). Este énfasis en lo uncanny, no hace sino destacar el peso de la historia en nuestro presente, puesto que es precisamente la reaparición del pasado en un nuevo contexto lo que provoca esta impresión, redefiniendo nuestro presente. Esta es la clave de la narración de la novela de Muñoz Molina también: esta sensación de encontrarse en un mundo familiar pero al mismo tiempo desfamiliarizado acompaña al protagonista durante toda la novela, hasta su desenlace, en donde el destello de la linterna de Rebeca Osorio-hija permite vislumbrar un futuro que trasciende, en cierta medida, su pasado.

Otro elemento en común entre Beltenebros y los relatos de Borges es la importancia del ambiente y el espacio laberíntico y claustrofóbico. En "El Sur", al descubrirse el primer cadáver, Lönrot acude con el comisario Treviranus a la escena del homicidio, donde está el cuerpo sin vida de un experto en la cábala, hallado previamente "casi desnudo bajo una gran capa anacrónica" (156). Una de las pistas que utiliza Scharlach para guiar a Lönrot hacia su trampa mortal se trata de la utilización, como apunta el título del cuento, de los puntos cardinales, además de un código numérico, como evidencian las constantes referencias especialmente a los dígitos tres y cuatro y sus derivados. De esta forma, el mapa que se empieza a delinear con el primer crimen que tiene lugar en el Hôtel du Nord continúa formándose hasta dirigir al detective a Triste-Le-Roy. Por otra parte, la descripción resulta significativa, al combinar referencias a espacios claustrofóbicos que se harán presentes tanto en Beltenebros como en "El Sur". La construcción donde se encuentra el hotel "muy notoriamente reúne la aborrecida blancura de un sanatorio, la numerada divisibilidad de una cárcel y la apariencia general de una casa mala" (155-56). El sanatorio es una dimensión protagónica en "El Sur", mientras que la "cárcel” y "la 
casa mala" podrían anticipar los dos espacios principales de la novela de Muñoz Molina: la casa mala estaría representada por la boîte Tabú y el Universal Cinema sería la cárcel literal de Rebeca Osorio y la metafórica de Darman.

El escéptico Darman de la novela de Muñoz Molina reacciona con incredulidad ante su azaroso encuentro con las novelas de la Rebeca Osorio de su pasado cuando busca a Andrade en un almacén abandonado: "Pero no era posible que esas cosas sucedieran, que el nombre de Rebeca Osorio aún durara en el mundo, bello y falso, anacrónico, sobrevivido en aquellas novelas y en aquel lugar inexplicable únicamente para que yo lo viera" (166). La naturaleza artificiosa del tiempo se entremezcla con los personajes, que parecen tener la capacidad de escindirse y amalgamarse, siguiendo la vena postmodernista, tal y como apunta Labanyi: “(...) the postmodernist deconstruction of identity does not mean that one has to abandon all attempts at definition: rather, it means recognition and contradiction. And, above, all identities are strategic constructions: neither inherent nor imposed, but negotiated" (Labanyi, “Postmodernism" 397). En este sentido, los tres conceptos que manejamos—el anacronismo, la duplicación y la simetría—no son más que reiteraciones que llaman la atención de los protagonistas y que provocan un resurgimiento de recuerdos que han estado reprimidos.

La vertiente postmodernista que Muñoz Molina sigue en su obra en que la identidad se ve duplicada o transformada es otro punto en común con Borges, donde también vemos que los personajes borgeanos poseen una identidad maleable. En “El Sur”, Dahlmann, durante su viaje en tren de vuelta a casa tras su estancia en el sanatorio, se dice a sí mismo que al día siguiente amanecerá en su hogar. Este pensamiento le provoca una extraña sensación desdobladora: “[E]ra como si a un tiempo fuera dos hombres" (215). Esta percepción revela el abigarrado y cambiante concepto de la individualidad que, además, parece incrementar las capacidades sensoriales del 
protagonista, pues el resto del párrafo se dedica a destacar, por medio de estructuras anafóricas antecedidas por "vio", una imagen nostálgica y gauchesca del hogar. La visión de Dahlmann subraya los elementos relacionados con la vida rural y la naturaleza: "Vio casas de ladrillo sin revocar ... vio jinetes en los terrosos caminos; vio zanjas y lagunas y hacienda; vio largas nubes luminosas ... y todas estas cosas eran casuales, como sueños de la llanura" (énfasis añadido 215). Al concluir esta reflexión visual con un símil que equipara esta sucesión de escenas con los "sueños de la llanura", se destaca la interpretación de su retorno al Sur como una visión quimérica.

Esta experiencia identitaria que vemos tanto en Beltenebros como en "El Sur" se duplica en "La muerte y la brújula" cuando Lönrot, convencido de que ha resuelto el misterio, se dirige a Triste-Le-Roy que se encuentra, significativamente, "al sur de la ciudad de mi cuento" (164). Por tanto, los protagonistas de estos relatos se dirigen, en tren, a un encuentro con el sur/pasado. También Lönrot, al llegar a su destino—en ambos sentidos de la palabra—refiere su experiencia de una forma análoga a la de Dahlmann en "El Sur", concatenando sucesivas percepciones visuales: "Vio perros, vio un furgón en una vía muerta, vio el horizonte, vio un caballo plateado que bebía el agua crapulosa de un charco" (énfasis añadido 165). El panorama visual que se despliega ante el ufano Lönrot, a diferencia de las contemplaciones de Dahlmann, tiene una connotación decididamente negativa, presagiando su funesto reencuentro con Scharlach, por medio de imágenes aciagas. En este sentido, la calificación de la vía como "muerta” y el agua que consume el animal como "crapulosa” resulta foránea, especialmente porque estos son adjetivos que suelen aplicarse a seres humanos. Por tanto, hay un proceso de truculenta personificación que presagia la muerte de Lönrot a manos de un resentido Scharlach.

La casa de Triste-Le-Roy, que sirve como escenario para la revelación final de los 
crímenes investigados por Lönrot, presenta dos Dianas, dos fuentes y otras duplicaciones formales. Al mismo tiempo, Scharlach se siente perseguido por un "Jano bifronte” (167), expresando la atmósfera claustrofóbica de su recuperación tras ser herido en los siguientes términos: "Llegué a abominar de mi cuerpo, llegué a sentir que dos ojos, dos manos, dos pulmones, son tan monstruosos como dos caras" (167). Este autorechazo se manifiesta también en "El Sur” y en Beltenebros. En el relato de Borges, Dahlmann, al verse sometido a una dolorosa cura, que es descrita como si de una tortura se tratara, el narrador revela el desprecio que siente hacia sí mismo durante su convalecencia física: “En esos días, Dahlmann minuciosamente se odió; odió su identidad, sus necesidades corporales, su humillación, la barba que le erizaba la cara" (213). Este intenso odio físico hacia uno mismo vincula a los personajes, transcendiendo los límites textuales.

De forma similar, en la novela de Muñoz Molina la joven Rebeca Osorio confiesa ante Darman que detesta su nombre, puesto que "[s]uena a falso, a cine" (239). Éste, tras un encuentro sexual con la muchacha plagado de ambigüedades, es incapaz de mirarla o de contemplarse en el espejo, avergonzado de su propio reflejo. Por un lado, el sometimiento de la identidad a otras personas, ya sea debido a una convalecencia o enfermedad, como es el caso de Scharlach y Dahlmann, frustra a los personajes que renuncian a su propia persona, incapaces de valerse por sí mismos, aunque sea temporalmente. Por otro, el desprecio de Rebeca Osorio hacia su propio nombre, seña esencial de la identidad, se debe a que su vida es una ficción, dominada y escrita por otros, mientras que la repugnancia de Darman ante su deleznable acción contra la joven Rebeca Osorio, no hace más que intensificar su culpabilidad por haber arruinado la relación de la Rebeca Osorio del pasado al asesinar a Walter. En todos estos casos, la identidad necesitará de un acto de afirmación para volver a ser aceptada: Scharlach engaña exitosamente a 
Lönrot en "La muerte y la brújula", Dahlmann acepta un duelo que supondrá su muerte—aunque sea soñada $-\mathrm{y}$ Rebeca Osorio acaba con la vida de Beltenebros, quien ha manejado los hilos de su vida y la de su madre. En cambio, la reconciliación de Darman consigo mismo es difícil de aseverar, si bien descubre la identidad del fantasma de su pasado, comprendiendo retrospectivamente que parte de su supuesta heroicidad y prestigio dentro del PCE se basan en el asesinato de un hombre inocente.

En Beltenebros la figura del doppelgänger prolifera, como he señalado, especialmente a través de las múltiples identidades que se adscriben—ya sea correcta o erróneamente—a la elusiva y malvada figura de Beltenebros así como la (con)fusión de Rebeca Osorio madre e hija. Además de estos personajes, las identidades se duplican en la repetición de acciones o experiencias por parte de diferentes personajes. Algunos de los protagonistas se sumen en un acceso febril. Cuando en los años cuarenta Valdivia huye después de ser herido, busca refugio en el Universal Cinema. Al igual que Andrade dos décadas más tarde, el fugitivo es víctima de una infección que trae consigo como uno de los síntomas más prominentes un estado febril. A Darman le acomete la fiebre cuando se encuentra en Florencia y en Madrid, bañando su estancia en ambas ciudades de una pátina irreal. Esta aflicción constante conspira contra él al reforzar su deseo, continuamente relegado, de volver a la burbuja protectora que representa su vida reconstruida y civil en Inglaterra. En las historias de Borges a los protagonistas también los aquejan altas temperaturas.

En "El Sur" el protagonista se sumerge en un profundo estado febril como consecuencia de un leve roce en su rostro - al comienzo del cuento es la esquina de una ventana abierta y, al final, una miga de pan lanzada en su dirección. A raíz de este primer contacto fortuito, Dahlmann parece habitar un mundo alucinatorio e infernal, exacerbado por su lectura de Las mil y una 
noches. Estas referencias constantes a la fiebre nos llevan a cuestionar la veracidad del viaje y la experiencia sureña de Dahlmann. Tanto el texto como el propio autor apuntan a esta lectura. Borges reconoce que "everything that happens after Dahlmann leaves the hospital could be interpreted as a hallucination when he is about to die of septicemia, as a fantastic vision of how he would have chosen to die" (cit. en Alazraki, Borges and the Kabbalah 66). Así, tanto el escritor argentino como Muñoz Molina usan el tropo de la enfermedad, en particular la fiebre, para (con)fundir la realidad y la ficción.

Además de estos elementos, podemos añadir otros indicios que apuntan a esta interpretación de la narración desde una perspectiva onírica o alucinatoria. La primera alusión a cierto trastorno se manifiesta durante la primera noche tras el accidente casero, cuando la narración señala que "desde aquella hora el sabor de todas las cosas fue atroz" (212). A continuación se hace mención de la fiebre conectando la perturbación de sus sentidos con su dolencia. Su percepción del tiempo se ralentiza — "Ocho días pasaron como ocho siglos”-y su sentimiento de extrañeza o alienación se mantiene después de su salida del hospital (212). La taza de café que se le prohíbe mientras está en el sanatorio y que bebe en el tren le provoca el pensamiento de que "aquel contacto era ilusorio" (214). La llegada a una estación que no es la familiar y que es totalmente desconocida para Dahlmann continúa enfatizando esta experiencia que, a pesar de contar con elementos comunes, también incluye una serie de sucesos y sensaciones que la sumen más aún en un mundo onírico.

La dimensión sobrenatural o mágica va en aumento a medida que nos vamos acercando al final del cuento. La presencia de un gaucho ajado y vestido a la antigua usanza parece ser una manifestación del recuerdo nostálgico que Dahlmann experimenta. Cuando su visión idealizadora es interrumpida por las burlonas migas de pan que le tiran, Dahlmann intenta 
ignorarlas: “[D]ecidió que nada había ocurrido y abrió el volumen de Las Mil y Una Noches, como para tapar la realidad" (218). A pesar de este esfuerzo, como una pesadilla de la que no se puede despertar, Dahlmann pierde el control sobre su fantasía y llega un momento en que sus acciones ya no dependen de sí mismo: "Era como si el Sur hubiera resuelto que Dahlmann aceptara el duelo" (219). La clave definitiva que demuestra la irrealidad de los acontecimientos que se narran viene dada en la conclusión:

Salieron, y si en Dahlmann no había esperanza, tampoco había temor. Sintió, al atravesar el umbral, que morir en una pelea a cuchillo, a cielo abierto y acometiendo, hubiera sido una liberación para él, una felicidad y una fiesta, en la primera noche del sanatorio, cuando le clavaron la aguja. Sintió que si él, entonces, hubiera podido elegir o soñar su muerte, ésta es la muerte que hubiera elegido o soñado.

Dahlmman empuña con firmeza el cuchillo, que acaso no sabrá manejar, y sale a la llanura. (220)

La elección en el primer párrafo de emplear en dos ocasiones unas construcciones verbales en pluscuamperfecto del subjuntivo, indican que la acción que se describe pertenece a una posibilidad del pasado, es decir, algo que no pudo tener lugar. La transición al presente y la incertidumbre que denota la combinación del adverbio de duda "acaso" con el futuro simple, obedece a la descripción de los sueños o a la narración fílmica, implicando una transición entre la hipótesis que se describe en el primer párrafo, con su supuesta realización soñadora en la última frase de la novela.

Si en "El Sur" se destaca la posibilidad de que Dahlmann realmente no volviera a salir del sanatorio y que, en vez de una muerte en un duelo, se debatiese entre la vida y la muerte en 
una cama de hospital, en "La muerte y la brújula" y Beltenebros también se da cabida a la creación de ficciones a través del simulacro y la impostura, conceptos claves del postmodernismo. Jean Baudrillard, uno de los proponentes de los conceptos de simulacro y simulación, introduce estos conceptos precisamente explorando un micro-relato de Borges, "Del rigor en la ciencia". Baudrillard asevera que "simulation corresponds to a short-circuit of reality and to its reduplication by signs" (182). En este sentido, la simulación y el simulacro, tanto en Borges como en Muñoz Molina, ponen de relieve la representación de la realidad que se encuentra ligada al pasado de forma más o menos exitosa. Así, en "El Sur" el elaborado plan trazado por Scharlach para dar caza a Lönrot da cabida a un crimen simulado que el avezado criminal representa con sus compinches para continuar creando un laberinto alrededor del detective. Si bien el tercer homicidio fue "un mero simulacro" (169), el asesinato de Yarmolinsky, según Scharlach, es cometido por Azevedo pues "medio siglo de violencia le había enseñado que lo más fácil y seguro era matar" (168). De forma similar, el segundo crimen implica el sacrificio del propio Azevedo por su traición. Irónicamente, esto supone que la primera impresión de Treviranus, que plantea a Lönrot la posibilidad de que se trate de una maniobra fingida, es la correcta. Asimismo, el hecho de que se subraye explícitamente en la narración que es carnaval—Treviranus piensa incluso que la llamada de un supuesto delator puede tratarse de una broma debido a esta festividad—es otro guiño sarcástico a la ceguera parcial del detective. Por tanto, "el razonador Erik Lönrot" (169), que rechaza esta posibilidad sin darle mayor importancia, manifiesta que su proceso deductivo no es infalible. Al desestimar las sospechas sugeridas por su compañero, decide ignorar la única rendija por donde la desconfianza podría haberle llevado a cuestionar esta cadena de asesinatos y, en consecuencia, a salvar su propia vida. Scharlach, una vez que atrapa a Lönrot, se deleita en desvelar los detalles 
de su entramado criminal, que incluye, al igual que en Beltenebros, la revelación de la múltiple identidad impostada que adopta Scharlach, ya que éste confiesa que "Gryphius-GinzbergGinsburg soy yo" (169) ${ }^{7}$. El simulacro, por tanto, es una herramienta mortal que sirve para engatusar a la víctima, planear su asesinato, y llevarlo a cabo.

La simulación se manifiesta en Beltenebros por medio de diversos personajes y recursos. La identidad dúplice y cambiante de Darman como, por un lado, vendedor en una tienda en Inglaterra con "una silenciosa familia que fingía aceptar las coartadas de mis desapariciones" y, por otro, célebre agente de lo que implícitamente se indica que es el movimiento de resistencia comunista, le obliga a perfeccionar su arte disimulador (281). Esta práctica se encuentra tan internalizada que el protagonista reconoce que " $[\mathrm{t}]$ ambién fingía cuando estaba solo y . . . no intervenía la voluntad ni casi la conciencia, sino un hábito de simulación tan antiguo como el que me inducía a pensar y a tener sueños en inglés" (137-38). Experto en estos subterfugios, su mirada es capaz de reconocer la representación de ficciones similares. Así, Darman contempla la figura de Rebeca Osorio-hija tumbada en la cama y no puede evitar percibirla "como un simulacro de otra mujer que no existió" (239). Durante su primera conversación con la joven, ya advierte este rasgo de su carácter: "Había en su actitud una cansada simulación" (214). En efecto, la muchacha se ve obligada a representar una vida que no es la suya y que incluye peinarse, maquillarse y vestirse como lo hacía su madre en los años cuarenta, antes de que Walter fuera asesinado. Severo Sarduy, en su estudio sobre la simulación, ahonda en las implicaciones de esta imitación: "El mimetismo borra los contornos, disuelve el cuerpo en el

\footnotetext{
${ }^{7}$ Rosa Sarabia, en su artículo que analiza el uso paródico del género policial que Borges emplea en el cuento, llama nuestra atención a los paralelos y diferencias que existen entre el relato borgeano y la obra de Poe "La carta robada", dado que Borges hace una referencia a Auguste Dupin, personaje del cuento de Poe. Es interesante notar la inversión de roles tradicionales que el escritor argentino lleva a cabo, pues, al contrario que en el género policiaco tradicional, en "La muerte y la brújula", la persona que describe y resuelve el misterio que esconden los asesinatos es el criminal, mientras que el detective resulta ser la víctima (Sarabia 10).
} 
espacio que lo rodea, lo asimila, lo identifica con su soporte; la escritura corporal, al contrario, lo marca, lo señala, lo destaca como objeto cifrado, perteneciente al lenguaje y ajeno a seres y cosas" (63-64). Esta imposición supone para la joven un desvanecimiento de su figura o una reificación, hasta que logra reivindicar su presencia, mediante el acto liberador de la conclusión, donde acaba con Beltenebros, la persona que la somete a esta identidad remedada. De forma similar, el protagonista, al relatar los eventos que rodearon el "caso Walter" deja ver que, ya entonces, desconfió de Valdivia pues “en su actitud de enfermo había una parte de simulación” (205). La simulación, en este sentido, conforma tanto la realidad como la ficción.

Además de la dimensión ficticia que supone este simulacro, se asocia esta representación fingida con un ambiente espectral y umbrío. Por una parte, el protagonista se identifica como una figura etérea cuando Rebeca Osorio explica su compleja relación con el próximo objetivo de Darman: "Quería hablar de Andrade y yo era un pretexto y un simulacro de sombra" (216). Por otra, en la confrontación entre Darman y Beltenebros en la conclusión de la novela, éste último le obliga a enfrentarse a su culpa sin justificaciones ni expiaciones, ya que confiesa que cuando él actuaba como Valdivia, habría dejado vivir a Walter por el amor que sentía hacia Rebeca Osorio. Aunque esta afirmación es difícil de creer ya que Ugarte-Validivia es responsable de que Darman ejecute a Walter, entre otros, todavía le echa en cara a Darman que él no tuviera tal compasión. En las tinieblas del Universal Cinema Darman intenta defenderse de la acusación, dándose cuenta de la inutilidad de su alegato: "Pero hablar en la oscuridad era como estar ya muerto y acordarse de los vivos repitiendo en el simulacro de la conversación palabras antiguas y perdidas, nombres lejanos de fantasmas que no existían en el mundo" $(293)^{8}$. Este proceso de

\footnotetext{
${ }^{8}$ En una aproximación similar a la del presente ensayo, Edward T. Gurski elabora un estudio comparativo entre Beatus Ille, otra novela de Muñoz Molina, y la obra borgeana. En el texto narrativo del español encontramos, de nuevo, una revelación identitaria final que reescribe hechos del pasado, pues el escritor Jacinto Solana, a quien se pensaba muerto desde hace años, no sólo reaparece vivo, sino que, al igual que Scharlach, entreteje una maraña
} 
fingimiento entraña la necesidad de llevar a cabo un cuestionamiento constante, no sólo dentro de la ficción sino también en la realidad presente, pues se sugiere que ficción y realidad no son tan distintas. Si tenemos en cuenta las capas de falsedad que envuelven el viaje al Sur de Dahlmann, la trampa criminal desarrollada por Scharlach y a los personajes de Beltenebros, vemos que el simulacro es un recurso esencial en la técnica narrativa tanto de Borges como de Muñoz Molina. A este respecto, es interesante señalar la aportación con respecto a la teoría del simulacro por parte de Baudrillard. Al aplicar su teoría, Baudrillard observa un aspecto importante y paradójico: "the hyperrealism of simulation is expressed everywhere by the real's striking resemblance to itself" (180). Cabe plantearse si, dado que la similitud entre lo verdadero y el simulacro es tan marcada, es necesario distinguir entre ambas o podemos simplemente aceptar que la ficción es una parte intrínseca y complementaria de la realidad, como parecen postular los relatos de Borges y la obra de Muñoz Molina.

La dimensión ilusoria que parece rodear a la realidad y su vínculo temporal con el pasado, destacados por los elementos explorados anteriormente, se ven magnificadas por las estructuras meándricas de estas obras. El laberinto, con sus caminos intrincados, sirve de enlace entre el pasado y el presente. Tal y como he mencionado con anterioridad, en Beltenebros Darman descubre que el Universal Cinema que fue escenario del "caso Walter" está conectado al boîte Tabú del "caso Andrade". El cine, como ha sugerido Ulrich Winter, actúa como cronotopo, además de acentuar las referencias fílmicas que hay en la novela (202). Este espacio es donde se resuelve la misteriosa identidad del hombre que se esconde entre las tinieblas donde se reescribe

\footnotetext{
laberíntica que consigue atrapar a Minaya. Gurski observa lo siguiente sobre esta revelación: "[H]e adds his final, Borgesian note: 'Piense, si lo prefiere, que este momento no existe.' Everything that Minaya sought has turned out to be false, a simulacrum of reality" (351). La realidad aquí se encuentra sometida a la simulación creada por otros.
} 
el pasado, a pesar de los esfuerzos de Beltenebros por confundir a Darman con pistas falsas ${ }^{9}$. En un movimiento opuesto pero igualmente efectivo, Lönrot es atraído a la casa de Triste-Le-Roy por medio de una serie fabricada de asesinatos reales. En "El Sur” Dahlmann se encuentra con su destino y con la muerte en un rústico y anticuado sur. Pasado y presente se entremezclan y combinan en un lugar significativo y específico.

Finalmente, podemos señalar el uso irónico de elementos que se supone que sirven para otorgar poder y fortaleza a los protagonistas. En "La muerte y la brújula” los excepcionales poderes deductivos de Lönrot son precisamente los que le llevan a su condenación, ya que en la deducción y seguimiento de las pruebas, cae en la trampa de Scharlach. Este proceso metódico tiene su base en el estudio cabalístico, provocando una inmersión inquisitiva en el mundo de la cábala por parte de Lönrot. Alazraki realiza una analogía que vincula este aspecto, tan prominente en la obra de Borges, con el proceso deductivo llevado a cabo por los lectores: "Ultimately, the hermeneutics of the Kabbalists is not different from any other method for reading a literary text: there is a literal meaning laid at its surface, and there are underlying meanings beneath that outer one" (Borges and the Kabbalah 11) ${ }^{10}$. Lönrot, interesantemente, es capaz de comprender el significado soterrado y complejo de los asesinatos, aunque no le es posible leer el sentido literal y superficial de los textos.

En “El Sur” la daga que el gaucho proporciona a Dahlmann será un arma de doble filo,

\footnotetext{
${ }^{9}$ Un empleo semejante de evidencias fabricadas semejantes surte el efecto contrario en "La muerte y la brújula" donde éstas sirven para atraer a Scharlach. Asimismo, Roberto González Echevarría en su artículo sobre "El jardín de los senderos que se bifurcan" se refiere a la afición de Borges por el empleo de pistas textuales ficticias (65n). ${ }^{10}$ La importancia que Borges le otorga al lector es consabida. Muñoz Molina expresa una perspectiva similar a la del escritor argentino cuando opina que es importante tener en cuenta "la conciencia del lector como un personaje, casi el personaje central, porque es en su imaginación donde tiene lugar el proceso de conocimiento, ese equilibrio que ha de ser muy riguroso, entre lo que se dice y lo que se calla, entre lo que ya se sabe y lo que todavía no se sabe, entre la verdad y la mentira. Por eso, cuando escribo, yo procuro situarme del lado del lector" (160-61). Esta identificación entre autor y lector desvela un interés por una literatura como herramienta no sólo de erudición, sino también de placer y entretenimiento.
} 
pues, aunque le sirve para protegerse, también será la razón de su muerte o, como el protagonista indica: "el arma, en su mano torpe, no servía para defenderlo, sino para justificar que lo mataran" (219). Si, como he sugerido, todo se trata de un sueño causado por su enfermedad, esta muerte que, según la perspectiva de Dahlmann, implica mayor heroísmo que morir por las complicaciones de una leve herida mal curada, es sólo posible, precisamente, por esa alucinación provocada por la fiebre. Igualmente, la poderosa visión nocturna de Beltenebros es, al mismo tiempo, su punto fuerte y su talón de Aquiles, ya que su condición de nictálope será la causa directa de su muerte. Por consiguiente, en todos estos casos hay un pharmakon que fortifica y destroza simultáneamente.

El vínculo entre Beltenebros y la ficción de Borges es evidente, particularmente en su conexión con "El Sur” y "La muerte y la brújula”. En primer lugar, esta interrelación, además de ser explícitamente reconocida por Muñoz Molina, queda patente en las referencias intertextuales y en los nombres así como en la multiplicidad de identidades que muestran estos personajes. En segundo lugar, la pesquisa detectivesca de "La muerte y la brújula" y Beltenebros obliga a los personajes a enfrentarse con su pasado. En "El Sur" la búsqueda interna del protagonista se resuelve drásticamente con la contribución de un gaucho que parece venir del pasado o del subconsciente del protagonista. La duplicación de los personajes y las ligazones que existen entre ellos sugieren que, con el objetivo de lidiar con el pasado, es necesario tener una doble- $-\mathrm{e}$ incluso triple_-identidad.

Con el objetivo de evadirse de - y en el caso de Muñoz Molina, trascender- este pasado que asedia a los protagonistas, en "El Sur” Dahlmann recurre a una fuga onírica, mientras que en "La muerte y la brújula" y Beltenebros se hace extenso uso del simulacro, difuminando de esta forma la separación entre realidad y ficción. Asimismo, la condición febril de los protagonistas 
constituye un síntoma físico de esta persecución del pasado que, además, se encuentra indefectiblemente unido al presente a través de estructuras laberínticas-ya sean físicas o metafóricas - y espacios que prueban que el presente y nuestra historia y memoria constituyen una espiral que magnifica de manera progresiva pequeños incidentes de nuestra vida anterior. En último lugar, las cualidades instrumentales y características de los protagonistas permiten su supervivencia pero sólo para, finalmente, causar su muerte. Tras analizar estos puntos de convergencia en la obra de ambos escritores, podemos concluir aseverando que la obra Beltenebros, por un lado, ilustra la influencia de Borges y la literatura latinoamericana en las letras españolas y, por otro, demuestra que el pasado es para Muñoz Molina un puente ineludible hacia el futuro. 


\section{Obras citadas}

Alazraki, Jaime. Borges and the Kabbalah. And other Essays on his Fiction and Poetry. Cambridge UP, 1988.

---. "Borges: Entre la modernidad y la postmodernidad.” Revista Hispánica Moderna, vol. 41, no.2, 1988, pp. 175-79.

---. "Relectura de 'El acercamiento a Almotásim.” Conjurados: Anuario Borgiano 1996, edited by Franco Maria Ricci. Centro de Estudios Jorge Luis Borges, 1996, pp. 32-39.

Borges, Jorge Luis. “El milagro secreto.” Ficciones. Ediciones Destino, 2004, pp. 171-81.

---. "El Sur.” Ficciones. Ediciones Destino, 2004, pp. 211-20.

---. "La forma de la espada.” Ficciones. Ediciones Destino, 2004, pp. 137-44.

---. “La muerte y la brújula.” Ficciones. Ediciones Destino, 2004, pp. 154-70.

---. “Pierre Menard, autor del Quijote.” Ficciones. Ediciones Destino, 2004, pp. 38-51.

---. “Kafka y sus precursores.” Otras inquisiciones. Alianza, 2007, pp. 162-66.

Baudrillard, Jean. "Simulacra and Simulations." Jean Baudrillard: Selected Writings, edited by Mark Poster. Stanford UP, 1988, pp. 166-84.

de Cervantes Saavedra, Miguel. Don Quijote de la Mancha. RAE, 2004.

Díaz Navarro, Epicteto. "El crepúsculo de los héroes en Beltenebros: De la novela de Antonio Muñoz Molina al film de Pilar Miró.” Castilla: Estudios de Literatura vol. 7, 2016, pp. 6984.

Fokkema, Douwe F. Literary History, Modernism, and Postmodernism (The Harvard University Erasmus Lectures, Spring 1983). John Benjamins, 1984.

Freud, Sigmund. "The Uncanny." Collected Papers. Vol. 4, edited by Joan Riviere. The Hogarth P, 1953, pp. 368-407.

García Márquez, Gabriel. Cien años de soledad. Espasa Calpe, 1993. 
González Echevarría, Roberto. "Borges en 'El jardín de los senderos que se bifurcan.” Borges: Desesperaciones aparentes y consuelos secretos, edited by Rafael Olea Franco. El Colegio de México, 1999, pp. 61-74.

Gurski, Edward T. “Antonio Muñoz Molina and Jorge Luis Borges: Buried Intertextualities in Beatus Ille." Bulletin of Hispanics Studies, vol. 77, 2000, pp. 343-57.

Hutcheon, Linda. "The Politics of Postmodernism: Parody and History." Cultural Critique, vol. 5, 1986-1987, pp. 179-207.

Labanyi, Jo. "History and Hauntology; or, What Does One Do with the Ghosts of the Past? Reflections on Spanish Film and Fiction on the Post-Franco Period.” Disremembering the Dictatorship: The Politics of Memory in the Spanish Transition to Democracy, edited by Joan Ramon Resina, Rodopi, 2000, pp. 65-82.

---. "Postmodernism and the Problem of Cultural Identity." Spanish Cultural Studies: An Introduction. The Struggle for Modernity, edited by Helen Graham and Jo Labanyi, Oxford UP, 1995, pp. 396-406.

López-Valero, Olga. "Historia y cultura popular en Beltenebros." Los presentes pasados de Antonio Muñoz Molina, edited by María-Teresa Ibáñez Ehrlich, Vervuet/Iberoamericana, 2000, pp. 151-76.

Mas, Pasqual. Beltenebros, de Muñoz Molina. Síntesis, 2002.

Muñoz Molina, Antonio. Beltenebros. Cátedra, 2004.

---. “Carlota Fainberg.” Cuentos de La isla del tesoro. Santillana, 1994.

---. "Discurso de inauguración del Congreso de ciudadanía hispánica de la literatura." Instituto Cervantes, 25 May 2015, congresosdelalengua.es/cartagena/inauguracion/ molina_m.htm 
---. "Una celebración de Borges/Un tributo a María Kodama." Instituto Cervantes de Nueva York, 20 May 2015. http://archivodigital.cervantes.es/fichas/centros/ nueva_york/homenaje_borges.htm

Nicol, Bran. The Cambridge Introduction to Postmodern Fiction. Cambridge UP, 2009.

Roffé, Reina. "Entrevista a Jorge Luis Borges." Cuadernos hispanoamericanos, vol. 585, 1999), pp. 7-11.

Sánchez López, Pablo. “La alternativa hispanoamericana: Las primeras novelas del ‘Boom’ en España.” Revista Hispánica Moderna, vol. 51, no.1, 1998, pp. 102-18.

Sarabia, Rosa. “'La muerte y la brújula' y la parodia borgeana del género policial.” Journal of Hispanic Philology, vol. 17, no.1, 1992, pp. 7-17.

Sarduy, Severo. La simulación. Monte Avila, 1982.

Waisman, Sergio. "The Thousand and One Nights in Argentina: Translation, Narrative, and Politics in Borges, Puig, and Piglia." Comparative Literature Studies, vol. 40, no.4, 2003, pp. 351-71.

Winter, Ulrich. "El cine, la máquina de escribir y el Teatro de la Memoria. Sobre una lógica de la referencia de los medios en Beltenebros." Los presentes pasados de Antonio Muñoz Molina, edited by María-Teresa Ibáñez Ehrlich, Vervuet /Iberoamericana, 2000. 